\title{
Sitagliptin as add-on therapy in insulin deficiency: biomarkers of therapeutic efficacy respond differently in type I and type 2 diabetes
}

This article was published in the following Dove Press journal:

Drug Design, Development and Therapy

13 February 2013

Number of times this article has been viewed

\section{Ottavio Giampietro \\ Chiara Giampietro \\ Luca Della Bartola \\ Maria Chiara Masoni \\ Elena Matteucci}

Department of Clinical and Experimental Medicine, University of Pisa, Pisa, Italy

Correspondence: Elena Matteucci

Department of Clinical and Experimental Medicine, University of Pisa, Via Roma 67, $56 \mid 26$ Pisa, Italy

Tel +39050993246

Fax +39050993520

Email elena.matteucci@med.unipi.it
Background: Sitagliptin has been proven to be effective and safe as add-on to insulin in adult patients with type 2 diabetes and absolute insulin deficiency. Recently, it has been suggested to extend the use of dipeptidyl-peptidase- 4 inhibitors to type 1 diabetes. The aim of this study was to evaluate and compare the effects of a long-term, fixed-dose combination of sitagliptin and metformin as add-on to insulin on body mass index, fasting plasma glucose, fructosamine, $\mathrm{HbA}_{1 \mathrm{c}}$, lipids, and daily dose of insulin in both type 1 diabetes and insulintreated type 2 diabetes.

Methods: We recruited 25 patients with type 1 diabetes (mean age $51 \pm 10$ years, mean disease duration $26 \pm 13$ years) and 31 insulin-treated type 2 diabetic patients (mean age $66 \pm 8$ years, mean disease duration $19 \pm 9$ years), who received sitagliptin with metformin as a fixed-dose combination $(50 / 1000 \mathrm{mg}$ once or twice daily) or sitagliptin (100 mg once daily, if intolerant to metformin) in addition to ongoing insulin therapy for $46 \pm 19$ weeks and $56 \pm 14$ weeks, respectively.

Results: After $21 \pm 9$ weeks, patients with type 1 diabetes had a significantly lower body mass index, fasting plasma glucose, fructosamine, $\mathrm{HbA}_{1 \mathrm{c}}$, and daily insulin requirement. After $49 \pm 17$ weeks, they maintained their weight loss and total daily insulin dose and showed a significant reduction in low-density lipoprotein cholesterol levels, whereas their $\mathrm{HbA}_{\mathrm{lc}}$ had returned to baseline values. In patients with type 2 diabetes, long-term treatment remained weight-neutral but had persistent beneficial effects on short-term, intermediate-term, and long-term biomarkers of metabolic control, as well as on low-density lipoprotein cholesterol levels and insulin requirement.

Conclusion: Clinical outcomes differed according to type of diabetes in terms of quality and over time. In type 2 diabetes, the combination therapy significantly improved metabolic control and the lipid profile, and decreased insulin requirements, even in the absence of clinically significant weight loss. In type 1 diabetes, the combined therapy only temporarily improved metabolic control, but significantly decreased body weight, low-density lipoprotein cholesterol levels, and insulin requirements.

Keywords: dipeptidyl-peptidase-4 inhibitors, drug therapy combination, metformin, synthetic analogs of insulin, diabetes mellitus, type 1 , type 2

\section{Introduction}

The available evidence strongly supports the therapeutic benefits of intensive glycemic control in diabetes mellitus, although this is difficult to achieve and maintain, especially in insulin-treated patients. ${ }^{1-3}$ The new dipeptidyl-peptidase-4 (DPP4) inhibitors have been widely accepted in the daily management of type 2 diabetes in view of their strategic advantages with regard to body weight, risk of hypoglycemia, and beta 
cell survival. ${ }^{4-7}$ By inhibiting degradation of the incretin hormones, DPP4 inhibitors enhance their glucose-stimulated insulin-secretory activity. Additional actions include inhibition of glucagon secretion, induction of satiety, delayed gastric emptying, and preserved beta cell mass. Although DPP4 inhibition is effective in improving glycemic status, particularly in mild and moderate type 2 diabetes where beta cell reserve is greater, currently some of these agents have been approved as add-on therapy to insulin. ${ }^{8}$

Sitagliptin has been proven to be effective and safe in combination with insulin in adult patients with type 2 diabetes and absolute insulin deficiency. ${ }^{9}$ Recently, it has been suggested to extend the use of DPP4 inhibitors to type 1 diabetes, ${ }^{10}$ as happened previously for metformin. ${ }^{11}$ The aim of the present study was to evaluate and compare the effects of a long-term ( $\geq 8$ weeks) fixed-dose combination of sitagliptin and metformin (unless metformin was not tolerated) as add-on to insulin on body mass, fructosamine, $\mathrm{HbA}_{1 \mathrm{c}}$, lipids, and daily dose of insulin in both type 1 diabetes and insulin-treated type 2 diabetes.

\section{Materials and methods}

Diabetic patients regularly attending the diabetic outpatient clinic of our department were eligible to participate in the study if they were $\geq 18$ years old, had had documented type 1 or type 2 diabetes for more than 5 years, were on stable multiple daily injection therapy, and had an $\mathrm{HbA}_{1 \mathrm{c}}>6.5 \%$. Subjects were excluded if they were on metformin or a glucagon-like peptide 1 agonist, had creatinine $>0.1 \mathrm{mmol} / \mathrm{L}$ or calculated creatinine clearance $<50 \mathrm{~mL} /$ minute, aspartate aminotransferase elevated more than three-fold above the normal upper limit, serious comorbidities, pregnancy, or history of drug or alcohol abuse. Diabetes mellitus was diagnosed according to American Diabetes Association criteria. ${ }^{1}$ Type 1 diabetes was confirmed by the presence of at least one of the three islet antibodies (glutamic acid decarboxylase, protein tyrosine phosphatase, or islet cell antibodies), fasting C-peptide $<0.4 \mathrm{ng} / \mathrm{mL}$, insulin monotherapy since diagnosis, and no history of oral hypoglycemic agents.

A fixed-dose combination of sitagliptin and metformin (50/1000 mg) was taken with meals; the starting dose was $50 / 1000 \mathrm{mg}$ (at breakfast) once daily, and was increased to a maximum of 100/2000 mg (50/1000 mg twice daily) unless metformin was not tolerated. Subjects were asked to maintain their current diet and physical activity, continue their current insulin-dosing regimen, and make changes to their insulin dose as usual on the basis of their blood glucose readings.
We recruited 25 patients with type 1 diabetes ( 15 women and 10 men, mean age $51 \pm 10$ years, mean disease duration $26 \pm 13$ years) and 31 insulin-treated type 2 diabetic patients (16 women and 15 men, mean age $66 \pm 8$ years, mean disease duration $19 \pm 9$ years). All patients with type 1 diabetes were on a four times daily insulin dose regimen, and patients with type 2 diabetes injected insulin 2-4 times daily. Twenty type 1 and 18 type 2 diabetic patients received the maximum daily dose of the fixed combination (100/2000 mg) in addition to ongoing insulin therapy. Due to limited tolerability, five type 2 diabetic patients received $50 / 1000 \mathrm{mg}$ once daily. Only sitagliptin $100 \mathrm{mg}$ once daily was added to insulin therapy in five type 1 diabetic patients and eight type 2 diabetic patients intolerant of metformin. Twelve type 1 diabetic patients received antihypertensive medication, ie, angiotensin-converting enzyme inhibitors and/or angiotensin II receptor blockers $(n=12)$, diuretics $(\mathrm{n}=8)$, beta-blockers $(\mathrm{n}=2)$, calcium channel blockers $(n=4)$, or other medication $(n=2)$, and 12 patients received statins. Twenty-six type 2 diabetic patients received antihypertensive medication, ie, angiotensin-converting enzyme inhibitors and/or angiotensin II receptor blockers $(n=21)$, diuretics $(n=16)$, beta-blockers $(n=6)$, calcium channel blockers $(n=11)$, or other medication $(n=3)$, and 21 patients received statins. Lipid-lowering medication did not change during follow-up.

Each subject provided their informed consent according to institutional guidelines. At each follow-up visit, height, weight, body mass index, blood pressure, and regular drug therapy (including mean total daily insulin dose), and self-reported rate of documented symptomatic hypoglycemia $(\leq 3.9 \mathrm{mmol} / \mathrm{L})$ in the 4 weeks before the visit were recorded.

Laboratory evaluation included complete blood count, fasting plasma glucose, fructosamine, $\mathrm{HbA}_{1 \mathrm{c}}$, high-density lipoprotein (HDL) cholesterol, low-density lipoprotein (LDL) cholesterol, triglycerides, creatinine clearance, uric acid, aspartate and alanine aminotransferase, gammaglutamyl transpeptidase, bilirubin, and urinary albumin excretion. The primary outcome measures were baseline and final values for body mass index, fasting plasma glucose, fructosamine, $\mathrm{HbA}_{1 \mathrm{c}}$, HDL cholesterol, LDL cholesterol, and triglycerides.

\section{Statistical analysis}

The statistical analysis was performed using Aabel 3 (Gigawiz, Oklahoma City, OK, USA). The results are given as the mean \pm standard deviation. The Student's paired 
$t$-test was used to compare screening variables at baseline versus intermediate or final visits. A $P$ value $<0.05$ was considered to be statistically significant for all analyses. Pearson's correlation and linear regression analysis were used to examine bivariate relationships between metabolic outcomes and predictor variables.

\section{Results}

The mean total duration of follow-up was $46 \pm 19$ weeks in type 1 patients and $56 \pm 14$ weeks in type 2 patients (Table 1). In subjects with type 1 diabetes, we observed a significant reduction in body mass index (mean weight loss $1.9 \pm 2.6 \mathrm{~kg}$ ), fructosamine, LDL cholesterol, and total daily insulin dose per $\mathrm{kg}$ body weight. In subjects with type 2 diabetes, fasting plasma glucose, fructosamine, $\mathrm{HbA}_{1 \mathrm{c}}$, LDL cholesterol, and total daily insulin dose per $\mathrm{kg}$ body weight decreased significantly, whereas body mass index remained substantially unchanged. In both groups, blood pressure, HDL cholesterol, triglycerides and other parameters considered did not change (data not shown).

A complete clinical and laboratory evaluation at an intermediate visit was available for 23 patients with type 1 diabetes ( $21 \pm 9$ weeks) and 30 patients with type 2 diabetes ( $27 \pm 12$ weeks). As shown in Table 2, after about 5 months of treatment for type 1 diabetes, the reduction in body mass index, fructosamine, and total daily insulin per $\mathrm{kg}$ body weight was already clearly observable. In contrast with

Table I Clinical and laboratory characteristics in patients with type $I$ and type 2 diabetes at baseline and final visit after combined therapy

\begin{tabular}{|c|c|c|c|}
\hline Characteristic & Baseline & $\begin{array}{l}\text { After } \\
\text { treatment }\end{array}$ & $P$ value \\
\hline \multicolumn{4}{|l|}{ Type I diabetes } \\
\hline $\mathrm{BMI}, \mathrm{kg} / \mathrm{m}^{2}$ & $26.5 \pm 3.3$ & $25.8 \pm 3.4$ & $<0.00$ I \\
\hline $\mathrm{FPG}, \mathrm{mmol} / \mathrm{L}$ & $1 \mathrm{I} .3 \pm 4.8$ & $10.5 \pm 3.8$ & $<0.5$ \\
\hline Fructosamine, $\mu \mathrm{mol} / \mathrm{L}$ & $365 \pm 53$ & $339 \pm 50$ & 0.004 \\
\hline $\mathrm{HbA}_{\mathrm{Ic}}, \%$ & $8.7 \pm 1.3$ & $8.7 \pm 1.2$ & $<0.5$ \\
\hline LDL cholesterol, $\mathrm{mmol} / \mathrm{L}$ & $2.6 \pm 0.8$ & $2.3 \pm 0.6$ & 0.015 \\
\hline Insulin dose, U/kg/day & $0.73 \pm 0.36$ & $0.60 \pm 0.24$ & $<0.001$ \\
\hline \multicolumn{4}{|l|}{ Type 2 diabetes } \\
\hline $\mathrm{BMI}, \mathrm{kg} / \mathrm{m}^{2}$ & $31.0 \pm 4.4$ & $30.7 \pm 4.3$ & 0.109 \\
\hline $\mathrm{FPG}, \mathrm{mmol} / \mathrm{L}$ & $11.3 \pm 3.8$ & $9.2 \pm 3.5$ & 0.001 \\
\hline Fructosamine, $\mu \mathrm{mol} / \mathrm{L}$ & $37 I \pm 4 I$ & $324 \pm 41$ & $<0.00$ I \\
\hline $\mathrm{HbA}_{\mathrm{Ic}}, \%$ & $9.3 \pm 0.9$ & $8.6 \pm 0.9$ & 0.002 \\
\hline LDL cholesterol, $\mathrm{mmol} / \mathrm{L}$ & $2.9 \pm 0.7$ & $2.4 \pm 0.8$ & 0.008 \\
\hline Insulin dose, U/kg/day & $0.51 \pm 0.24$ & $0.42 \pm 0.21$ & $<0.001$ \\
\hline
\end{tabular}

Notes: The values are expressed as mean \pm standard deviation; comparison by paired $t$-test (two-tailed $P$ value).

Abbreviations: BMI, body mass index; FPG, fasting plasma glucose; LDL, low-density lipoprotein. the final results, $\mathrm{HbA}_{1 \mathrm{c}}$ values were improved significantly, while the change in LDL cholesterol levels still did not reach statistical significance. When comparing the final measurements with the intermediate determinations, the results showed that there were statistically significant differences in body mass index (which further decreased) and $\mathrm{HbA}_{1 \mathrm{c}}$ percentage (which returned to baseline levels). In type 2 diabetes, after about 6 months of treatment, body mass remained the same, but fasting plasma glucose, fructosamine, $\mathrm{HbA}_{1 \mathrm{c}}$, LDL cholesterol, and total daily insulin per $\mathrm{kg}$ of body weight were already decreased. The results show that after initial improvement at 6 months of treatment, $\mathrm{HbA}_{1 \mathrm{c}}$ values worsened over subsequent months, but did not return to baseline levels.

In type 1 diabetic patients, there was a direct correlation between the decrease in LDL cholesterol levels and the decrease in daily insulin requirement $\left(\mathrm{R}^{2}=0.18, P=0.034\right.$, Figure 1) as well as between fructosamine levels and daily insulin dose corrected for body weight $\left(\mathrm{R}^{2}=0.11\right.$, $P=0.017)$.

It is noteworthy that during the mean $46 \pm 12$ weeks before the baseline visit, patients with type 1 diabetes did not show any statistically significant difference in mean body mass index $\left(26.2 \pm 3.2 \mathrm{~kg} / \mathrm{m}^{2}\right)$, fasting plasma glucose $(12.5 \pm 6.4 \mathrm{mmol} / \mathrm{L})$, fructosamine $(374 \pm 61 \mu \mathrm{mol} / \mathrm{L}), \mathrm{HbA}_{\mathrm{lc}}$ $(8.8 \% \pm 1.6 \%)$, LDL cholesterol $(97 \pm 24 \mathrm{mg} / \mathrm{dL})$, or daily insulin dose $(0.70 \pm 0.25 \mathrm{IU} / \mathrm{kg})$ compared with baseline. During the mean $55 \pm 16$ weeks before the baseline visit, patients with type 2 diabetes did not show any statistically significant difference in mean body mass index $\left(30.2 \pm 5.6 \mathrm{~kg} / \mathrm{m}^{2}\right)$, fasting plasma glucose $(11.9 \pm 4.8 \mathrm{mmol} / \mathrm{L})$, fructosamine $(356 \pm 44 \mu \mathrm{mol} / \mathrm{L}), \mathrm{HbA}_{1 \mathrm{c}}(9.3 \% \pm 0.8 \%)$, or LDL cholesterol $(104 \pm 34 \mathrm{mg} / \mathrm{dL})$, whereas the total daily insulin dose was significantly lower $(0.45 \pm 0.23 \mathrm{IU} / \mathrm{kg}, P<0.001)$ compared with values at baseline.

\section{Discussion}

The fixed-dose combination of sitagliptin and metformin as add-on therapy (with or without ongoing insulin) has been shown to reduce $\mathrm{HbA}_{1 \mathrm{c}}$ significantly in patients with type 2 diabetes and inadequate glycemic control. ${ }^{12,13}$ Long-term safety and tolerability were maintained. ${ }^{14}$ Our data confirm that longterm use of a combination of metformin and insulin is weightneutral $(-0.9 \pm 2.9 \mathrm{~kg})$, and has beneficial effects on short-term, intermediate-term, and long-term biomarkers of metabolic control, ie, $\mathrm{HbA}_{1 \mathrm{c}}(-0.6 \% \pm 1.0 \%)$ and LDL cholesterol levels $(-12 \pm 23 \mathrm{mg} / \mathrm{dL}[-31 \mathrm{mmol} / \mathrm{L}]) \cdot{ }^{15}$ Although administration of sitagliptin did not significantly alter the lipid profile in type 2 
Table 2 Clinical and laboratory characteristics in 23 patients with type I diabetes and 30 type 2 diabetes who had a complete clinical and laboratory evaluation at an intermediate visit between baseline and final visit

\begin{tabular}{|c|c|c|c|c|c|}
\hline Characteristic & Baseline & $\begin{array}{l}\text { After } 21 \pm \\
9 \text { weeks }\end{array}$ & $P$ value & $\begin{array}{l}\text { After } 49 \pm \\
\text { I } 7 \text { weeks }\end{array}$ & $P$ value \\
\hline \multicolumn{6}{|l|}{ Type I diabetes } \\
\hline $\mathrm{BMI}, \mathrm{kg} / \mathrm{m}^{2}$ & $26.1 \pm 3.2$ & $25.7 \pm 3.3$ & 0.014 & $25.5 \pm 3.3^{\mathrm{a}}$ & 0.004 \\
\hline FPG, mmol/L & $11.0 \pm 4.9$ & $8.1 \pm 5.5$ & 0.008 & $10.3 \pm 3.7$ & $<0.5$ \\
\hline Fructosamine, $\mu \mathrm{mol} / \mathrm{L}$ & $368 \pm 55$ & $327 \pm 39$ & $<0.001$ & $341 \pm 52$ & 0.013 \\
\hline $\mathrm{HbA}_{\mathrm{Ic}}, \%$ & $8.7 \pm 1.4$ & $8.0 \pm 0.9$ & $<0.001$ & $8.7 \pm 1.3^{b}$ & $<0.5$ \\
\hline LDL cholesterol, mmol/L & $2.5 \pm 0.6$ & $2.3 \pm 0.7$ & 0.162 & $2.2 \pm 0.5$ & 0.049 \\
\hline Insulin dose, U/kg/day & $0.72 \pm 0.38$ & $0.56 \pm 0.24$ & $<0.00$ I & $0.59 \pm 0.25$ & 0.001 \\
\hline Characteristic & Baseline & $\begin{array}{l}\text { After } 27 \pm \\
12 \text { weeks }\end{array}$ & $P$ value & $\begin{array}{l}\text { After } 56 \pm \\
14 \text { weeks }\end{array}$ & $P$ value \\
\hline \multicolumn{6}{|l|}{ Type 2 diabetes } \\
\hline $\mathrm{BMI}, \mathrm{kg} / \mathrm{m}^{2}$ & $31.2 \pm 4.4$ & $30.9 \pm 4.6$ & 0.142 & $30.8 \pm 4.4$ & 0.068 \\
\hline FPG, $\mathrm{mmol} / \mathrm{L}$ & $11.4 \pm 3.9$ & $9.5 \pm 2.9$ & 0.006 & $9.3 \pm 3.4$ & 0.002 \\
\hline Fructosamine, $\mu \mathrm{mol} / \mathrm{L}$ & $37 I \pm 42$ & $313 \pm 30$ & $<0.001$ & $324 \pm 42$ & $<0.001$ \\
\hline $\mathrm{HbA}_{1 \mathrm{c}}, \%$ & $9.3 \pm 0.9$ & $8.2 \pm 0.8$ & $<0.001$ & $8.6 \pm 0.9^{b}$ & 0.002 \\
\hline LDL cholesterol, mmol/L & $2.7 \pm 0.7$ & $2.5 \pm 0.8$ & 0.046 & $2.4 \pm 0.8$ & 0.007 \\
\hline Insulin dose, U/kg/day & $0.5 I \pm 0.24$ & $0.4 \mathrm{I} \pm 0.22$ & $<0.001$ & $0.43 \pm 0.21$ & $<0.001$ \\
\hline
\end{tabular}

Notes: The values are expressed as mean \pm SD; the two $P$ value columns refer to the comparison by paired $t$-test (two-tailed $P$ value) between intermediate or final visit, respectively, versus baseline visit; letter superscripts indicate significant differences ( $P<0.05$ and $\left.{ }^{\mathrm{b}} P<0.0 \mathrm{l}\right)$ between final versus intermediate visit.

Abbreviations: BMI, body mass index; FPG, fasting plasma glucose; LDL, low-density lipoprotein.

diabetics, follow-up durations ranged from 4 to 26 weeks, ${ }^{8}$ and our findings suggest that longer time periods are necessary to observe changes in lipid metabolism. Moreover, only a small proportion of trials have reported data on LDL cholesterol during DPP4 inhibition, but a recent meta-analysis indicates a possible beneficial effect of DPP4 inhibitors on cholesterol that could contribute to the associated reduction in cardiovascular risk. ${ }^{16}$ Further, metformin per se may have an effect on LDL cholesterol that is independent of glucose-lowering, but the reductions were smaller $(-22 \mathrm{mmol} / \mathrm{L})$ than we observed. ${ }^{17}$

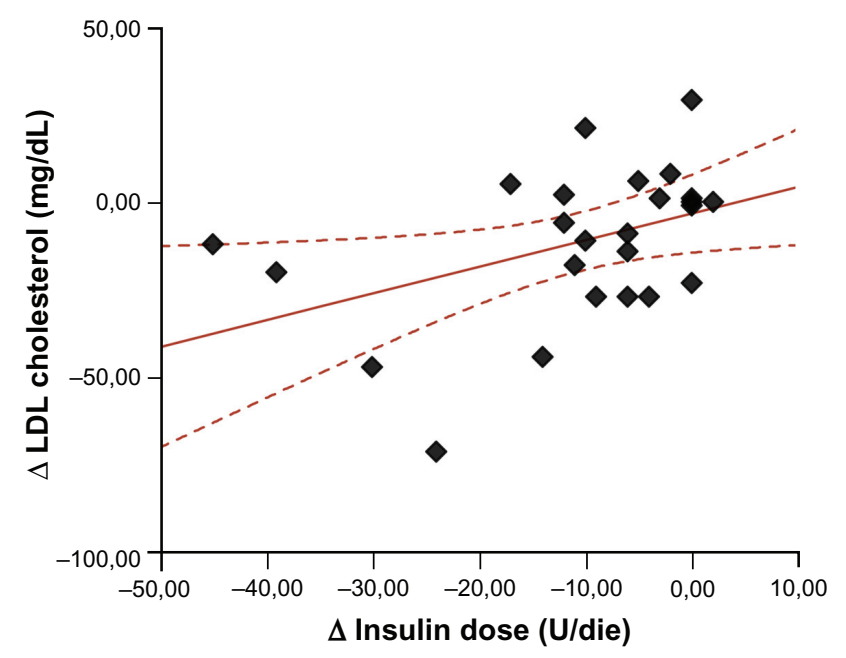

Figure I Linear relationship between the decrease in LDL cholesterol levels ( $\Delta$ LDL cholesterol) and the decrease in daily insulin requirement ( $\Delta$ insulin dose) in patients with type I diabetes.

Abbreviation: LDL, low-density lipoprotein.
Contrary to previous protocols where the insulin dose remained stable throughout the study, ${ }^{15,18}$ we observed a decrease in total daily insulin dose $(-8 \pm 8 \mathrm{U})$ at 6 months of treatment that was maintained until 13 months. Self-monitoring and selfadaptation of insulin dose could explain why our study group did not experience an increased incidence of hypoglycemia as observed by Vilsbøll et al. ${ }^{18}$ The fact that sitagliptin as an add-on to insulin is effective and safe in reducing blood glucose levels, even in absolutely insulin-deficient patients, suggests involvement of extrapancreatic mechanisms that are independent of the glucagon-like peptide 1 axis. ${ }^{9}$ The rationale for extending the use of incretin therapies to early type 1 diabetes relies on the assumption that these drugs, in addition to their action on insulin secretion, may preserve or increase beta-cell mass, and the negative findings of a pilot trial of exenatide and anti-CD25 antibodies in patients with long-standing type 1 diabetes. ${ }^{19,20}$

So far, there are very few reports on the effects of DPP4 inhibitors in type 1 diabetes and none of them involve long-term treatment. The effect of DPP4 inhibition by vildagliptin on the glucagon counter-regulatory response to hypoglycemia in type 1 diabetes is under investigation. ${ }^{21}$ After 4 weeks of treatment, sitagliptin $100 \mathrm{mg} /$ day reduced blood glucose, $\mathrm{HbA}_{1 \mathrm{c}}$ values, and total daily insulin dose in 20 adult subjects with type 1 diabetes, ${ }^{10}$ just as observed previously using the insulin sensitizer metformin. ${ }^{11}$ This is the first study to evaluate the long-term efficacy of sitagliptin, alone or in combination with metformin, when added to insulin 
therapy in adult patients with type 1 diabetes. Contrary to expectations, clinical outcomes differed according to diabetes type in terms of quality and over time. After a mean $21 \pm 9$ weeks, patients with type 1 diabetes had significantly lower body mass index, fasting plasma glucose, fructosamine, $\mathrm{HbA}_{1 \mathrm{c}}$, and daily insulin requirement. After a mean $49 \pm 17$ weeks, they maintained their weight loss and total daily insulin dose, and showed a significant reduction in LDL cholesterol levels, whereas their $\mathrm{HbA}_{1 \mathrm{c}}$ had returned to baseline values.

The DPP4 inhibitors are generally weight-neutral, and the weight loss sometimes observed has been attributed to novel potential mechanisms, including an influence on postprandial lipid and lipoprotein metabolism via inhibition of triglyceride absorption from the gut and/or promoting sympathetically mediated lipid mobilization and catabolism in the postabsorptive state. ${ }^{22}$ These effects could be more pronounced in younger type 1 diabetic patients. Metformin, which has been found to reduce the daily insulin dose requirement (-6.6 $\mathrm{U})$ in type 1 diabetes without any significant reduction in $\mathrm{HbA}_{1 \mathrm{c}}{ }^{23}$ may have contributed to our presently observed daily reduction of $8 \mathrm{U}$. According to a recent meta-analysis, ${ }^{23}$ metformin was associated with a nonsignificant effect on $\mathrm{HbA}_{1 \mathrm{c}}$ in type 1 diabetics, but potential (albeit inconsistent) benefits included weight loss (1.7-6.0 kg in three of six studies) and total cholesterol reduction $(0.3-0.41 \mathrm{mmol} / \mathrm{L}$ in three of seven studies). Sixteen weeks of treatment with metformin did not change the final LDL cholesterol concentrations in 15 overweight patients with type 1 diabetes. ${ }^{24}$ One year of treatment with metformin reduced total and LDL cholesterol in 47 patients with type 1 diabetes by approximately $0.3 \mathrm{mmol} / \mathrm{L}$ (after adjustment for statin use). ${ }^{25}$ The discordance over time between $\mathrm{HbA}_{1 \mathrm{c}}$ and fructosamine observed in type 1 diabetes is hard to explain. To date, few studies have evaluated this topic, although it has been suggested that the discrepancies seen could reflect not only a difference in glycation target turnover times, but also the difference in physiologic compartments. ${ }^{26,27}$ The positive relationship between fructosamine and daily insulin dose per $\mathrm{kg}$ suggests a contributing role of improved insulin sensitivity.

\section{Limitations}

Our data in type 1 diabetic patients suggest that DPP4 inhibition, alone or in combination with metformin, caused only temporary improvement in glycemic control, but did achieve persistent reductions in body mass, insulin requirement, and LDL cholesterol. However, the magnitude of LDL cholesterol-lowering cannot be attributed to metformin alone. Despite the length of follow-up, the results of our study cannot be generalized to other groups because of the lack of a control arm, the small sample size, and personalized drug dose and composition. However, our data provide reflection points to design future clinical trials aimed at addressing outcomes of DPP4 inhibition in type 1 diabetes.

\section{Conclusion}

Our present findings confirm that a combination of sitagliptin-metformin and insulin therapy significantly improves metabolic control and the lipid profile, and decreases insulin requirements in type 2 diabetics, even in the absence of clinically significant weight loss. On the contrary, the same combined therapy improves metabolic control only temporarily in type 1 diabetics, but significantly decreases body weight, LDL cholesterol levels, and insulin requirements. Use of DPP4 inhibitors may also be effective in patients with type 1 diabetes, but future studies are needed to evaluate their long-term efficacy and safety, as well as specific mechanisms of action in patients with an absolute deficiency of insulin secretion.

\section{Disclosure}

The authors report no conflicts of interest in this work.

\section{References}

1. American Diabetes Association. Standards of medical care in diabetes - 2012. Diabetes Care. 2012;35 Suppl 1:S11-S63.

2. Braga MF, Casanova A, Teoh H, et al; Diabetes Registry to Improve Vascular Events [DRIVE] Investigators. Poor achievement of guidelines - recommended targets in type 2 diabetes: findings from a contemporary prospective cohort study. Int J Clin Pract. 2012;66(5):457-464.

3. Vouri SM, Shaw RF, Waterbury NV, Egge JA, Alexander B. Prevalence of achievement of A1c, blood pressure, and cholesterol (ABC) goal in veterans with diabetes. J Manag Care Pharm. 2011;17(4):304-312.

4. Neumiller JJ, Wood L, Campbell RK. Dipeptidyl peptidase-4 inhibitors for the treatment of type 2 diabetes mellitus. Pharmacotherapy. 2010;30(5):463-484.

5. Phillips LK, Prins JB. Update on incretin hormones. Ann NY Acad Sci. 2011;1243:E55-E74.

6. Matteucci E, Giampietro O. Dipeptidyl peptidase-4 (CD26): knowing the function before inhibiting the enzyme. Curr Med Chem. 2009;16(23):2943-2951.

7. Matteucci E, Giampietro O. Dipeptidyl peptidase-4 inhibition: linking chemical properties to clinical safety. Curr Med Chem. 2011;18(31):4753-4760.

8. Rizos EC, Ntzani EE, Papanas N, et al. Combination therapies of DPP4 inhibitors and GLP1 analogues with insulin in type 2 diabetic patients: a systematic review. Curr Vasc Pharmacol. June 22, 2012. [Epub ahead of print.]

9. Kutoh E. Sitagliptin is effective and safe as add-on to insulin in patients with absolute insulin deficiency: a case series. J Med Case Rep. 2011;5:117.

10. Ellis SL, Moser EG, Snell-Bergeon JK, Rodionova AS, Hazenfield RM, Garg SK. Effect of sitagliptin on glucose control in adult patients with type 1 diabetes: a pilot, double-blind, randomized, crossover trial. Diabet Med. 2011;28(10):1176-1181. 
11. George P, McCrimmon RJ. Potential role of non-insulin adjunct therapy in type 1 diabetes. Diabet Med. July 18, 2012. [Epub ahead of print.]

12. Dhillon S. Sitagliptin: a review of its use in the management of type 2 diabetes mellitus. Drugs. 2010;70(4):489-512.

13. Chwieduk CM. Sitagliptin/metformin fixed-dose combination in patients with type 2 diabetes mellitus. Drugs. 2011;71(3):349-361.

14. Williams-Herman D, Engel SS, Round E, et al. Safety and tolerability of sitagliptin in clinical studies: a pooled analysis of data from 10,246 patients with type 2 diabetes. BMC Endocr Disord. 2010;10:7.

15. Arnolds S, Dellweg S, Clair J, et al. Further improvement in postprandial glucose control with addition of exenatide or sitagliptin to combination therapy with insulin glargine and metformin: a proof-of-concept study. Diabetes Care. 2010;33(7):1509-1515.

16. Monami M, Lamanna C, Desideri CM, Mannucci E. DPP-4 inhibitors and lipids: systematic review and meta-analysis. Adv Ther. 2012;29(1): 14-25.

17. Gin H, Roudaut MF, Vergnot V, Baillet L, Rigalleau V. Effect of metformin on fibrinolytic parameters in insulin-treated, type 2 diabetic patients. Diabetes Metab. 2003;29(5):505-508.

18. Vilsbøll T, Rosenstock J, Yki-Järvinen H, et al. Efficacy and safety of sitagliptin when added to insulin therapy in patients with type 2 diabetes. Diabetes Obes Metab. 2010;12(2):167-177.

19. Bosi E. Time for testing incretin therapies in early type 1 diabetes? J Clin Endocrinol Metab. 2010;95(6):2607-2609.
20. Rother KI, Spain LM, Wesley RA, et al. Effects of exenatide alone and in combination with daclizumab on beta-cell function in long-standing type 1 diabetes. Diabetes Care. 2009;32(12):2251-2257.

21. Foley JE, Ligueros-Saylan M, He YL, et al. Effect of vildagliptin on glucagon concentration during meals in patients with type 1 diabetes. Horm Metab Res. 2008;40(10):727-730.

22. Boschmann M, Engeli S, Dobberstein K, et al. Dipeptidyl-peptidase-IV inhibition augments postprandial lipid mobilization and oxidation in type 2 diabetic patients. J Clin Endocrinol Metab. 2009;94(3):846-852.

23. Vella S, Buetow L, Royle P, Livingstone S, Colhoun HM, Petrie JR. The use of metformin in type 1 diabetes: a systematic review of efficacy. Diabetologia. 2010;53(5):809-820.

24. Khan AS, McLoughney CR, Ahmed AB. The effect of metformin on blood glucose control in overweight patients with type 1 diabetes. Diabet Med. 2006;23(10):1079-1084.

25. Lund SS, Tarnow L, Astrup AS, et al. Effect of adjunct metformin treatment on levels of plasma lipids in patients with type 1 diabetes. Diabetes Obes Metab. 2009;11(10):966-977.

26. True MW. Circulating biomarkers of glycemia in diabetes management and implications for personalized medicine. J Diabetes Sci Technol. 2009;3(4):743-747.

27. Cohen RM, Holmes YR, Chenier TC, Joiner CH. Discordance between $\mathrm{HbA}_{1 \mathrm{c}}$ and fructosamine: evidence for a glycosylation gap and its relation to diabetic nephropathy. Diabetes Care. 2003;26(1):163-167.
Drug Design, Development and Therapy

\section{Publish your work in this journal}

Drug Design, Development and Therapy is an international, peerreviewed open-access journal that spans the spectrum of drug design and development through to clinical applications. Clinical outcomes, patient safety, and programs for the development and effective, safe, and sustained use of medicines are a feature of the journal, which

\section{Dovepress}

has also been accepted for indexing on PubMed Central. The manuscript management system is completely online and includes a very quick and fair peer-review system, which is all easy to use. Visit http://www.dovepress.com/testimonials.php to read real quotes from published authors.

Submit your manuscript here: http://www.dovepress.com/drug-design-development-and-therapy-journal 